\title{
BMJ Open Prospective evaluation of an ultrathin strut biodegradable polymer-coated sirolimus-eluting stent: 12 months' results from the S-FLEX UK registry
}

\author{
Anirban Choudhury, ${ }^{1}$ Scot Garg, ${ }^{2}$ Jamie Smith, ${ }^{3}$ Andrew Sharp, ${ }^{4}$ \\ Sergio Nabais de Araujo, ${ }^{5}$ Anoop Chauhan, ${ }^{6}$ Nikhil Patel, ${ }^{7}$ Benjamin Wrigley, ${ }^{8}$ \\ Sudipta Chattopadhyay (D), ${ }^{9}$ Azfar G Zaman ${ }^{10}$
}

To cite: Choudhury A, Garg S, Smith J, et al. Prospective evaluation of an ultrathin strut biodegradable polymercoated sirolimus-eluting stent: 12 months' results from the S-FLEX UK registry. BMJ Open 2019;9:e026578. doi:10.1136/ bmjopen-2018-026578

- Prepublication history for this paper is available online. To view these files, please visit the journal online (http://dx.doi. org/10.1136/bmjopen-2018026578).

Received 16 September 2018 Revised 01 September 2019 Accepted 03 September 2019

Check for updates

(C) Author(s) (or their employer(s)) 2019. Re-use permitted under CC BY-NC. No commercial re-use. See rights and permissions. Published by BMJ.

For numbered affiliations see end of article.

Correspondence to

Dr Azfar G Zaman;

azfar.zaman@nuth.nhs.uk

\section{ABSTRACT}

Objective To prospectively evaluate safety and efficacy of the ultrathin strut biodegradable polymer-coated Supraflex sirolimus-eluting stent (S-SES) in 'real world' patient population requiring percutaneous coronary intervention (PCl).

Methods National, prospective, multicentre, singlearm, all-comers, observational registry of 469 patients treated with S-SES from July 2015 and November 2016 in 11 centres in UK. Primary endpoint was target lesion failure (TLF) at 12 months (cardiac death, target vessel myocardial infarction (MI) or clinically driven target lesion revascularisation (TLR)). Secondary endpoints included safety and performance outcomes at 12 months-overall stent thrombosis (ST), all-cause mortality, any MI, target vessel failure (TVF) and major adverse cardiac events (MACE-composite of cardiac death, MI, emergent or repeat revascularisation).

Results At 12 months, the primary endpoint occurred in $11(2.4 \%)$ of 466 patients, consisting of $4(0.9 \%)$ cardiac deaths, $3(0.6 \%)$ target vessel $\mathrm{Ml}$ and $7(1.5 \%)$ TLR. Secondary endpoints findings included all-cause mortality in $6(1.3 \%)$, TVF of $14(3 \%)$, no definite ST, $1(0.2 \%)$ probable ST and $3(0.6 \%)$ possible ST. Overall MACE was observed in 18 (3.9\%).

Conclusions The S-FLEX UK registry showed that the S-SES is safe with a low incidence of TLF in routine clinical practise in patients with coronary artery disease being treated by $\mathrm{PCl}$.

\section{INTRODUCTION}

Drug-eluting stents (DES) reduce neointimal proliferation and restenosis compared with bare-metal stents. ${ }^{12}$ However, the persistence of adverse events with both first-generation and contemporary permanent polymer-based DES presents an opportunity for iterative improvement. ${ }^{3-5}$ These include development of new metal alloys with thin struts, improved stent design and development of bioresorbable polymers. ${ }^{6-10}$

The potential link between durable polymer and late adverse events prompted
Strengths and limitations of this study

- The S-FLEXUK registry provides reassuring evidence that the ultrathin strut biodegradable polymer-coated sirolimus-eluting Supraflex stent can be safely and effectively used in routine clinical practice in UK patients with coronary artery disease being treated by percutaneous coronary intervention (PCl).

- The findings add to the emerging evidence that ultrathin strut biodegradable polymer stents can be used safely for $\mathrm{PCl}$ in routine clinical practice with the potential of further reducing target lesion failure.

- This is a non-randomised observational study of relatively small patient population with the inherent limitations of such studies. Nevertheless, the findings are consistent with other studies using the same product.

- The follow-up period was 12 months, and a longer period of follow-up would allow for more accurate assessment of very late stent thrombosis.

development of biodegradable polymers to reduce inflammatory response, facilitating re-endothelialisation and minimising risk of thrombus formation and late restenosis. ${ }^{11} 12$ Furthermore, first-generation DES with thickstrut design, are associated with more thrombotic events in ex vivo and experimental models. ${ }^{13} 14$ Newer DES technologies, with progressively thinner stent struts and biodegradable polymers promise additional benefit in terms of earlier re-endothelialisation and reduced restenosis. ${ }^{1516}$

In this multicentre UK registry, the objective was to assess safety and outcomes at 12 months of the CE-approved Supraflex (Sahajanand Medical Technologies (SMT) Pvt Ltd, Surat, India), a biodegradable polymer-coated SES, ultrathin $(60 \mu \mathrm{m})$ cobalt-chromium (Co-Cr) stent for the treatment of coronary artery disease (CAD) treated in routine clinical practice. 


\section{METHODS}

\section{Study design and patient population}

The S-FLEX UK registry was a prospective, observational, multicentre, postmarketing registry designed to evaluate the safety and efficacy of the Supraflex sirolimus-eluting stent (S-SES) in a 'real-world' patient population. The study enrolled 469 patients from July 2015 until November 2016 in 11 centres in UK. All patients over the age of 18, undergoing percutaneous coronary intervention (PCI) with at least one study stent, according to guidelines for revascularisation, irrespective of indication, disease location or complexity, were eligible for enrolment. In keeping with its real-world design, exclusion criteria were minimal and included patients with a high-probability of non-adherence to the follow-up requirements (due to social, psychological or medical reasons); females of childbearing age; those with planned surgery within 6 months of PCI unless dual antiplatelet therapy (DAPT) could be maintained throughout the peri-surgical period; those participating in another study that has not completed the primary endpoint or that clinically interfered with the current registry requirements and those with a known intolerance to aspirin, any P2Y12 drug, heparin, bivalirudin, cobalt, chromium, sirolimus or any other analogue or derivative, or contrast media. The registry, design and procedures complied with the principles of good clinical practice and the Declaration of Helsinki and were approved by the local ethics committee of each participating institution.

Patient and public involvement: All patients provided informed consent for the procedure and subsequent data collection and analysis for the research purposes. Patient and public were not involved in the designing of the registry, recruitment or conducting the registry.

\section{Device description}

The S-SES is a balloon-expandable stent using a medical grade cobalt-chromium alloy with ultra-thin struts of $60 \mu \mathrm{m}$ and crowns which are linked together by flexible 'S' links to provide flexibility and improved deliverability. The coating layer, applied on the conformal surface of the stent with a mean thickness of $4-5 \mu \mathrm{m}$, comprises sirolimus, at a concentration of $1.4 \mu \mathrm{g} / \mathrm{mm}^{2}$, blended together with biodegradable polymeric matrix (poly L-lactide, 50/50 poly DL-lactide-co-glycolide and polyvinyl pyrrolidone). The polymer facilitates programmed release such that $70 \%$ of the drug is released within 7 days and the remaining released over 48 days. The polymers retain their properties for a limited period and then gradually degrade into biologically inert molecules and excreted via normal metabolic pathways over 9-12 months. In addition, the device has a top protective layer that protects from light and moisture preventing premature drug release (figure 1). The device is available in diameters of 2.0, 2.25, 2.5, 2.75, 3.0, 3.50, 4.0 and $4.5 \mathrm{~mm}$ and in lengths increasing in $4 \mathrm{~mm}$ intervals from 8 to $48 \mathrm{~mm}$. Across the range, the strut thickness is $60 \mu \mathrm{m}$.
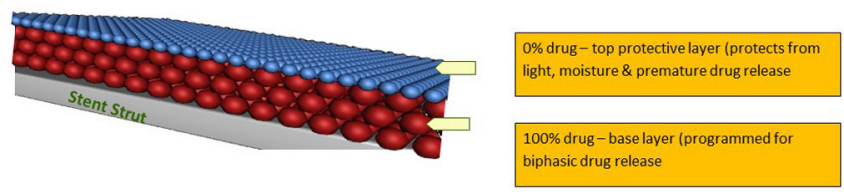

Figure 1 Bio-degradable polymer matrix of Supraflex sirolimus-eluting stent. Drug dose: $1.4 \mu \mathrm{g} / \mathrm{mm}^{2}$. Unique biodegradable polymer matrix: poly L-lactide, $50 / 50$ poly DLlactide-co-glycolide and polyvinyl pyrrolidone. Total coating thickness of $4-5 \mu \mathrm{m}$.

\section{Study procedure}

Standard interventional techniques were used to treat the lesion, with predilatation and postdilatation, procedural anticoagulation, use of glycoprotein IIb/IIIa inhibitors and duration of DAPT left to the operator's discretion.

\section{Data collection and follow-up}

Patient demographic data, lesion characteristics, procedure details and antithrombotic regimens were collected from each centre as per the prespecified case report form.

Follow-up was obtained at 12 months $( \pm 30$ days) after the index procedure by hospital visit $(14 \%)$ or telephonic follow-up. During follow-up consultations, information about patients' clinical condition, adverse events, hospitalisations and changes to concomitant (cardiac and antiplatelet) drugs were collected. Details of the above were further corroborated with review of the patients' electronic records and/or contacting the general practitioner.

Angiographic data were recorded for patients readmitted with ischaemia. For patients readmitted for ischaemia who underwent angiographic re-examination within 1 year, image analysis was performed to determine whether disease progression had occurred at the previously stented segment, including peri-stent areas $2 \mathrm{~mm}$ adjacent to the stent, or was limited to arterial segments remote from the stented region. If repeat angiography was performed $<30$ days after successful stent placement during the index procedure and demonstrated a significant stenosis or subacute stent thrombosis (ST) in the target vessel, the subject was considered an acute failure. If angiography took place $\geq 30$ days after the index procedure and demonstrated restenosis of the target vessel and/or target lesion in association with objective evidence of recurrent ischaemia, the angiogram was analysed according to the secondary endpoints.

All events were investigator reported at site with no independent clinical events committee; however, site monitoring was performed to ensure continued protocol compliance and accurate data reporting by Psephos Biomedica (Sussex Innovation Centre, University of Sussex, Brighton BN1 9SB, UK).

\section{Study endpoints}

The primary endpoint of the study was target lesion failure (TLF) at 12 months: a composite of cardiac death, target vessel myocardial infarction (MI) or clinically driven target lesion revascularisation (TLR) by percutaneous 
or surgical methods. Secondary endpoints assessed at 12 months included: overall ST; any death; any MI; any repeat revascularisation; target vessel failure (TVF) (a composite of cardiac death, target vessel MI or clinically driven TVR) and major adverse cardiac events (MACE-a composite of cardiac death, any MI, emergent or repeat revascularisation).

\section{Statistical analysis}

The sample size of subjects was selected to be similar to the patient numbers enrolled in the S-CORE registry. ${ }^{17}$ Data are presented using descriptive statistical methods. Continuous variables are presented as mean $\pm \mathrm{SD}$, whereas categorical variables are expressed as percentages. All data were processed using the SPSS V.15

\section{RESULTS}

\section{Baseline, lesion and patient characteristics}

The S-FLEX registry enrolled 469 patients from 11 centres in UK between the prespecified recruitment periods of July 2015 to November 2016. Three patients withdrew consent and 12 were lost to follow-up leaving 454 (97.4\%) patients for 12 months' clinical follow-up.

Baseline patient, lesion and procedural characteristics are shown in tables 1 and 2. Consistent with the all-comers design and reflective of a high-risk population active smoking, presence of diabetes, medical history of MI and revascularisation was noted in a quarter while over half had hypertension and hyperlipidaemia. Not all participating centres had a primary angioplasty service thereby explaining the lower number of patients with ST-elevation myocardial infarction that were recruited. However, in line with contemporary UK practice, the main indication for revascularisation was acute coronary syndrome $(59.7 \%) .{ }^{18}$ The mean number of lesions per patient was $1.23 \pm 0.5$, with $>10 \%$ of these lesions bifurcations or chronic total occlusions. The mean number of stents deployed per patient was $1.48 \pm 1.0$, with average length of coronary artery stented was $32.99 \pm 24.70 \mathrm{~mm}$. Overall device implantation success on the lesion was $98.6 \%$.

\section{Clinical outcomes}

Patient outcomes at 30 day, 6 months and 12 months are shown in table 3 . The rate of the primary endpoint of TLF was $2(0.4 \%)$ and $8(1.7 \%)$ at 30 days and 6 months, respectively. At 12 months, the components of TLF, cardiac death was observed in $4(0.9 \%)$, target vessel MI in $3(0.6 \%)$ and TLR in $7(1.5 \%)$. Cumulative TLF-free survival, at 12 months' follow-up, determined by the Kaplan-Meier method, was $97.4 \%$ as shown in figure 2 .

Secondary endpoints findings included all-cause mortality in $6(1.3 \%)$ and TVF in $14(3 \%)$. According to ARC definition, overall ST was observed in $4(0.8 \%)$ including no definite ST, $1(0.2 \%)$ probable ST and 3 $(0.6 \%)$ possible ST. Overall MACE were observed in 18 $(3.9 \%)$ patients.
Table 1 Baseline characteristics of the study population

n (\%) unless stated

\begin{tabular}{|c|c|}
\hline Patient characteristics & $n=466$ \\
\hline Age, mean $\pm S D$ (years) & $64.8 \pm 10.4$ \\
\hline Male & $350(75.1 \%)$ \\
\hline Body mass index $\left(\mathrm{kg} / \mathrm{m}^{2}\right)$ & $28.9 \pm 6.1$ \\
\hline Diabetes mellitus & $113(24.2 \%)$ \\
\hline Insulin requiring & $30(6.2 \%)$ \\
\hline Non-insulin requiring & $83(18.0 \%)$ \\
\hline Hypertension & $237(50.9 \%)$ \\
\hline Hypercholesterolemia & $251(53.9 \%)$ \\
\hline Family history of CAD & $226(48.5 \%)$ \\
\hline Current smoker & $120(25.8 \%)$ \\
\hline Renal insufficiency & $10(2.1 \%)$ \\
\hline Peripheral vascular disease & $17(3.6 \%)$ \\
\hline Congestive heart failure & $12(2.6 \%)$ \\
\hline Previous transient ischaemic attack & $12(2.6 \%)$ \\
\hline Previous stroke & $17(3.6 \%)$ \\
\hline Previous myocardial infarction & $127(27.3 \%)$ \\
\hline Previous $\mathrm{PCl}$ & $108(23.2 \%)$ \\
\hline Previous CABG & $18(3.9 \%)$ \\
\hline Acute coronary syndromes & $278(59.7 \%)$ \\
\hline Unstable angina & $187(40.2 \%)$ \\
\hline Silent ischaemia & $10(2.1 \%)$ \\
\hline NSTEMI & $58(12.5 \%)$ \\
\hline STEMI & $23(4.9 \%)$ \\
\hline Stable angina & $188(40.3 \%)$ \\
\hline Lesion characteristics & $\mathrm{n}=573$ lesions \\
\hline $\begin{array}{l}\text { Number of lesions per patient } \\
(\text { mean } \pm S D)^{*}\end{array}$ & $1.23( \pm 0.5)$ \\
\hline \multicolumn{2}{|l|}{ Target vessel } \\
\hline Left main stem & $7(1.2 \%)$ \\
\hline Left anterior descending & $249(43.5 \%)$ \\
\hline Left circumflex & $119(20.8 \%)$ \\
\hline Right coronary artery & 197 (34.4\%) \\
\hline Saphenous vein graft & $1(0.2 \%)$ \\
\hline Re-stenotic lesion & $16(2.8 \%)$ \\
\hline Bifurcation & $61(10.6 \%)$ \\
\hline Total occlusion & $75(13.1 \%)$ \\
\hline
\end{tabular}

CABG, coronary artery bypass grafting; CAD, coronary artery disease; NSTEMI, nonST elevation myocardial infarction; $\mathrm{PCl}$, percutaneous coronary intervention; STEMI, ST-elevation myocardial infarction.

\section{DISCUSSION}

This UK multicentre real-world registry of the thin strut, cobalt-chromium, biodegradable polymer S-SES demonstrated safety with a low incidence of TLF and ST at 12 months. 
Table 2 Procedural characteristics

\begin{tabular}{ll} 
Mean \pm SD unless stated & \\
\hline Procedural characteristics & $\mathrm{n}=691$ stents \\
No. of stents per patient & $1.48 \pm 1.0$ \\
No. of stents per lesion & $1.21 \pm 0.5$ \\
Mean stent length & $22.48 \pm 7.6$ \\
Mean stent diameter & $3.01 \pm 0.4$ \\
Predilatation, $\mathrm{n}(\%)$ & $471(82.2)$ \\
Postdilatation, $\mathrm{n}(\%)$ & $394(68.8)$ \\
Total stent length per patient & $32.99 \pm 24.70$ \\
Device success $(\%)$ & 98.6 \\
\hline
\end{tabular}

Concerns related to impaired healing and persistent inflammation associated with first-generation durable polymer DES, led to the development of improved polymers, metallic platform technologies and thinner struts. $^{3-10} 14$ The change in stent platform from stainless steel $(132-140 \mu \mathrm{m})$ to chromium alloys $(81-91 \mu \mathrm{m})$, reduced both procedural and late target vessel MI by about $40 \%-80 \% .^{19-22}$ The BIOFLOW V study compared the ultrathin strut $(60 \mu \mathrm{m})$ bioresorbable polymer



Figure 2 Kaplan-Meier curve of target lesion failure.

sirolimus-eluting Orsiro stent with the thin strut $(81 \mu \mathrm{m})$ durable polymer everolimus-eluting Xience stent and reported an approximate further $40 \%$ reduction in target vessel MI in favour of Orsiro ${ }^{10}$ The Orsiro stent polymer degrades over a 2 year span and thus the observed outcome differences at 1 year between the Orsiro and Xience stents are possibly largely driven by the difference in strut thickness rather polymer durability. Pooled analysis of large multicentre randomised trials reported lower risk of TVR

Table 3 Hierarchical and non-hierarchical subject counts of adverse events through 12 months (intent-to-treat population)

\begin{tabular}{|c|c|c|c|}
\hline $\mathrm{n}(\%)$ & 30 days & 6 months & 12 months \\
\hline \multicolumn{4}{|l|}{ Hierarchical events } \\
\hline TLF & $2(0.4)$ & $8(1.7)$ & $11(2.4)$ \\
\hline Cardiac death & $1(0.2)$ & $3(0.6)$ & $4(0.9)$ \\
\hline Target-vessel MI & $1(0.2)$ & $3(0.6)$ & $3(0.6)$ \\
\hline Target-lesion revascularisation & $0(0)$ & $5(1.1)$ & $7(1.5)$ \\
\hline Target vessel failure & $2(0.4)$ & $11(2.4)$ & $14(3.0)$ \\
\hline Major adverse cardiovascular events & $4(0.9)$ & $14(3.0)$ & $18(3.9)$ \\
\hline \multicolumn{4}{|l|}{ Non-hierarchical events } \\
\hline Death & $1(0.2)$ & $1(0.2)$ & $6(1.3)$ \\
\hline Cardiac death & $1(0.2)$ & $3(0.6)$ & $4(0.9)$ \\
\hline Non-cardiac death & $0(0.0)$ & $1(0.2)$ & $2(0.4)$ \\
\hline \multicolumn{4}{|l|}{ Myocardial infarction } \\
\hline Target vessel & $1(0.2)$ & $3(0.6)$ & $3(0.6)$ \\
\hline Non-target vessel & $2(0.4)$ & $3(0.6)$ & $4(0.9)$ \\
\hline \multicolumn{4}{|l|}{ Revascularisation } \\
\hline Target lesion revascularisation & $1(0.2)$ & $5(1.1)$ & $7(1.5)$ \\
\hline Target vessel revascularisation & $1(0.2)$ & $10(2.2)$ & $14(3.0)$ \\
\hline Non target vessel revascularisation & $2(0.4)$ & $4(0.8)$ & $6(1.2)$ \\
\hline Stent thrombosis & $1(0.2)$ & $3(0.6)$ & $4(0.9)$ \\
\hline Definite ST & $0(0.0)$ & $0(0.0)$ & $0(0.0)$ \\
\hline Probable ST & $1(0.2)$ & $1(0.2)$ & $1(0.2)$ \\
\hline Possible ST & $0(0.0)$ & $2(0.4)$ & $3(0.6)$ \\
\hline
\end{tabular}

MACE, major adverse cardiac events (composite of cardiac death, any MI, emergent or repeat revascularisation); MI, myocardial Infarction; ST, stent thrombosis; TLF, target lesion failure (composite of cardiac death, target vessel MI or clinically driven TLR); TVF, target vessel failure (composite of cardiac death, target vessel MI and TVR); TVR, target vessel revascularisation. 
and very late ST associated with biodegradable polymers compared with durable polymer-coated DES. ${ }^{23}$ However, it remains debatable whether this reduction of adverse events is a class effect of biodegradable polymers and may well be influenced by additional factors including stent strut thickness, polymer composition, distribution and load. $^{2425}$

Studies assessing the Supralimus-Core (previous version of the S-SES with the same strut thickness, polymer and drug concentration) reported reassuring vessel healing properties by optical coherence tomography at 4 months, ${ }^{26}$ along with satisfactory 1-year TLR of $1.1 \%$ along with MACE of $3.4 \%$ in real-world patients. ${ }^{17}$

The S-SES is an improved version of the Supralimus-Core SES with replacement of the rigid interlink/joint of the Supralimus-Core SES with a highly flexible 'S-link', which increases flexibility and deliverability. Preliminary evaluation of clinical and angiographic outcomes of the Supraflex stent in the MANIPAL-FLEX Study reported a TLR of $2.1 \% .{ }^{27}$ Angiographic in-stent late lumen loss, a dependable predictor of the long-term clinical efficacy of DES, ${ }^{28}$ was observed to be $0.18 \pm 0.23 \mathrm{~mm}$ with the Supraflex stent at 9 months in keeping with currently used effective DES systems. ${ }^{29-31}$

The subsequent retrospective, multicentre FLEX registry that included 995 unselected patients treated with the S-SES across nine centres in India reported a 12-month MACE of $3.7 \% .^{32}$ This included TLR of $0.7 \%$, definitive ST of $0.3 \%$ and overall ST of $1.1 \%$ at 12 months. Late ST remains a major concern even in contemporary DES and has been shown to be dependent on lack of strut coverage. ${ }^{33}$ In the FLEX registry OCT subgroup analysis, the authors reported $98.1 \%$ strut coverage at 6 months with the S-SES, that compared favourably with the 91.5\% and $94.1 \%$ strut coverage reported with Promus Element and Xience DES. ${ }^{34}$ The authors also reported S-SES to have an excellent healing index of 4.8 (1.022.9) comparing favourably with BioMatrix (35.2 \pm 25.0$)$,
Cypher (43.3 \pm 36.2$)$, Resolute (18.7 \pm 20.4$)$ and the Xience (10.8 \pm 15.3$)$ DES systems. ${ }^{35} 36$

In this registry, 12-month TLF of $2.4 \%$ and TLR of $1.5 \%$ is in keeping with the previous findings of the S-SES in the MANIPAL-FLEX and FLEX registries. These findings are encouraging when compared with the 12-month TLR and TLF of contemporary DES systems (figure 3). ${ }^{1022}$ 37-40 The promising clinical outcomes with the S-SES might be attributed to the combination of its ultrathin struts, biodegradable polymer and unique platform design. Extensive strut coverage within 4-6 months and low 'healing index' provide possible explanations for low ST and TLR rates. ${ }^{41}$ The relative safety and efficacy of the S-SES seen in this registry was confirmed by the TALENT (Thin strut sirolimus-eluting stent in All comers' population vs Evorolimus-eluting ste $n t$ ) study.

\section{Study limitations}

This was a non-randomised observational study of relatively small patient population with the inherent limitations of such studies. Nevertheless, the findings were consistent with other studies using the same product and complications at 12 months were qualitatively similar to contemporary DES. The end points were not adjudicated by a core laboratory, but all events reported were verified by external, qualified clinical trial monitors. No ECG was performed as part of the 12-month FU and majority of the follow-up was via telephonic questionnaire raising the possibility of under-reporting of endpoints. However, the study endpoints were 'clinically driven' and every effort was made to capture clinical events by reviewing the patients' electronic health records in addition to the in person/telephonic follow-up.

\section{CONCLUSIONS}

The S-FLEX UK registry provides evidence that the S-SES can be used safely and effectively in routine clinical practice in UK patients with CAD being treated by PCI.

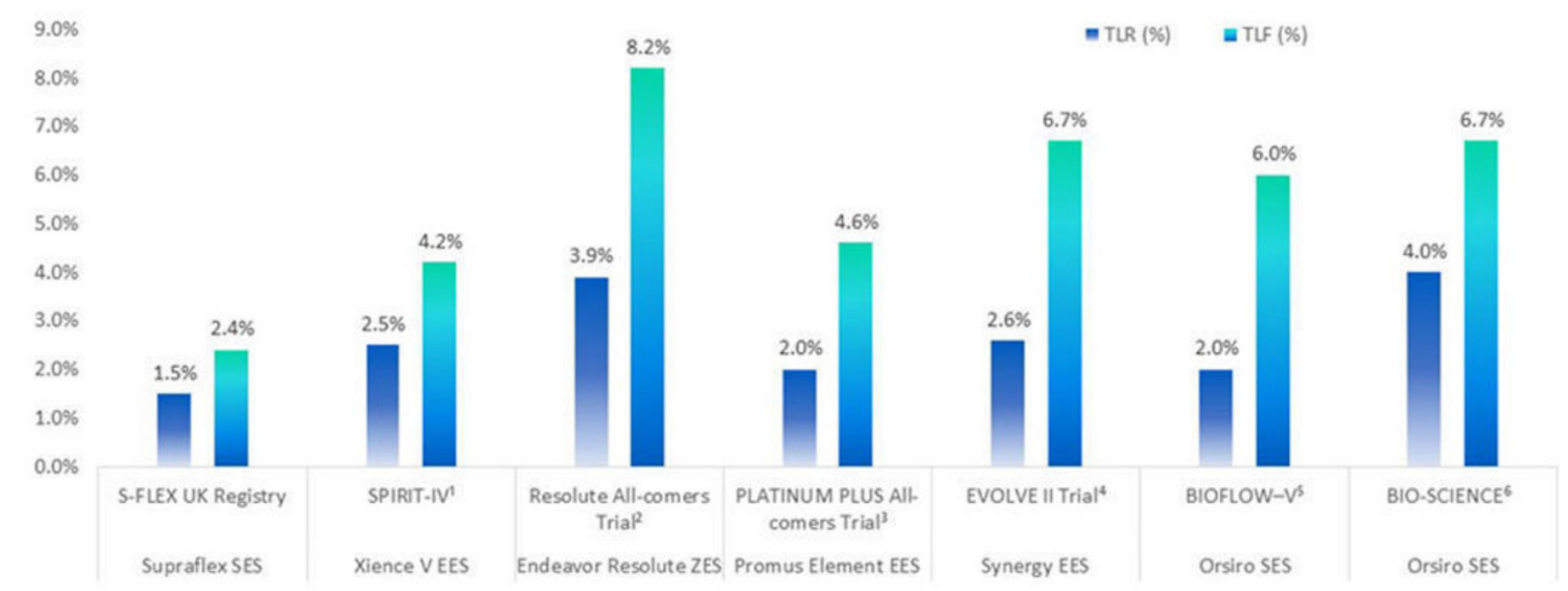

Figure 3 12-Month target lesion revascularisation and target lesion failure of contemporary stents. ${ }^{1-6}$ See references. $^{10} 2237-40$ 
Author affiliations

${ }^{1}$ Department of Cardiology, Cardiff and Vale University Health Board, Cardiff, UK

${ }^{2}$ Department of Cardiology, Royal Blackburn Hospital, Blackburn, UK

${ }^{3}$ Department of Cardiology, Raigmore Hospital, Inverness, UK

${ }^{4}$ Department of Cardiology, Royal Devon and Exeter Hospital, Exeter, UK

${ }^{5}$ Department of Cardiology, Salisbury District Hospital, Salisbury, UK

${ }^{6}$ Department of Cardiology and Institute of Cellular Medicine, Blackpool Victoria Hospital, Blackpool, UK

${ }^{7}$ Department of Cardiology, Eastbourne District General Hospital, Eastbourne, UK

${ }^{8}$ Department of Cardiology, The Heart and Lung Centre, Wolverhampton, UK

${ }^{9}$ Department of Cardiology, Milton Keynes University Hospital NHS Foundation Trust,

Milton Keynes, UK

${ }^{10}$ Freeman Hospital, Newcastle Upon Tyne, UK

Contributors The authors (ACho, SG, JS, AS, SNA, ACha, NP, BW, SC and AGZ) were principal investigators in their respective institutes and were involved in recruiting patients, authenticity of the data, dealing with queries and adjudicating any SAE. All authors (as mentioned above) were involved in drafting of the manuscript. ACho, SG and AGZ were responsible for the final version and overall content of the manuscript.

Funding This study was supported by SMT Pvt Ltd, Surat, India.

Competing interests None declared.

Patient consent for publication Not required.

Ethics approval Local ethics committee/institutional review board (at each institution).

Provenance and peer review Not commissioned; externally peer reviewed.

Data availability statement Data are available upon reasonable request.

Open access This is an open access article distributed in accordance with the Creative Commons Attribution Non Commercial (CC BY-NC 4.0) license, which permits others to distribute, remix, adapt, build upon this work non-commercially, and license their derivative works on different terms, provided the original work is properly cited, appropriate credit is given, any changes made indicated, and the use is non-commercial. See: http://creativecommons.org/licenses/by-nc/4.0/.

\section{ORCID iD}

Sudipta Chattopadhyay http://orcid.org/0000-0002-6421-6762

\section{REFERENCES}

1 Colombo A, Drzewiecki J, Banning A, et al. Randomized study to assess the effectiveness of slow- and Moderate-Release polymerbased paclitaxel-eluting stents for coronary artery lesions. Circulation 2003;108:788-94.

2 Moses JW, Leon MB, Popma JJ, et al. Sirolimus-Eluting stents versus standard stents in patients with stenosis in a native coronary artery. N Engl J Med 2003;349:1315-23.

3 Daemen J, Wenaweser P, Tsuchida K, et al. Early and late coronary stent thrombosis of sirolimus-eluting and paclitaxel-eluting stents in routine clinical practice: data from a large two-institutional cohort study. Lancet 2007;369:667-78.

4 Kimura T, Morimoto T, Nakagawa Y, et al. j-Cypher registry Investigators. very late stent thrombosis and late target lesion revascularization after sirolimus-eluting stent implantation: five-year outcome of the j-Cypher registry. Circulation 2012:125:584-91.

5 Claessen BE, Beijk MA, Legrand V, et al. Two-Year clinical, angiographic, and intravascular ultrasound follow-up of the XIENCE $\checkmark$ everolimus-eluting stent in the treatment of patients with de novo native coronary artery lesions. Circulation 2009;2:339-47.

6 Nakazawa G, Otsuka F, Nakano M, et al. The pathology of neoatherosclerosis in human coronary implants: bare-metal and drug-eluting stents. J Am Coll Cardiol 2011;57:1314-22.

7 Otsuka F, Vorpahl M, Nakano M, et al. Pathology of second-generation everolimus-eluting stents versus first-generation sirolimus- and paclitaxeleluting stents in humans. Circulation 2014;129:211-23.

8 Otsuka F, Yahagi K, Ladich E, et al. Hypersensitivity reaction in the US food and drug Administration-approved second-generation drugeluting stents: histopathological assessment with ex vivo optical coherence tomography. Circulation 2015;131:322-4.

9 Otsuka F, Byrne RA, Yahagi K, et al. Neoatherosclerosis: overview of histopathologic findings and implications for intravascular imaging assessment. Eur Heart J 2015;36:2147-59.
10 Kandzari DE, Mauri L, Koolen JJ, et al. Ultrathin, bioresorbable polymer sirolimus-eluting stents versus thin, durable polymer everolimus-eluting stents in patients undergoing coronary revascularisation (BIOFLOW V): a randomised trial. Lancet 2017;390:1843-52.

11 Joner M, Finn AV, Farb A, et al. Pathology of drug-eluting stents in humans: delayed healing and late thrombotic risk. J Am Coll Cardiol 2006;48:193-202.

12 Hofma SH, van der Giessen WJ, van Dalen BM, et al. Indication of long-term endothelial dysfunction after sirolimus-eluting stent implantation. Eur Heart J 2006;27:166-70.

13 Morton AC, Crossman D, Gunn J. The influence of physical stent parameters upon restenosis. Pathol Biol 2004;52:196-205.

14 Kolandaivelu K, Swaminathan R, Gibson WJ, et al. Stent thrombogenicity early in high-risk interventional settings is driven by stent design and deployment and protected by polymer-drug coatings. Circulation 2011;123:1400-9.

15 Briguori C, Sarais C, Pagnotta P, et al. In-Stent restenosis in small coronary arteries: impact of strut thickness. J Am Coll Cardiol 2002:40:403-9.

16 Jabara R, Geva S, Ribeiro H, et al. A third generation ultra-thin strut cobalt chromium stent: histopathological evaluation in porcine coronary arteries. Eurolntervention 2009;5:619-26.

17 Chandwani P, Abhyankar AD, Prajapati JS, et al. Clinical performance of the Cobalt-Chromium biodegradable polymer coated sirolimuseluting stent in an unselected real-world population. Int J Clin Med 2014;05:206-15.

18 BCIS. Update, 2016. Available: https://www.bcis.org.uk/education/ bcis-audit-report-adult-intervention-excl-tavi-calender-year

19 Kandzari DE, Leon MB, Popma JJ, et al. Comparison of zotarolimuseluting and sirolimus-eluting stents in patients with native coronary artery disease. J Am Coll Cardiol 2006;48:2440-7.

20 Stone GW, Midei M, Newman W, et al. Spirit III Investigators. Comparison of an everolimus-eluting stent and a paclitaxel-eluting stent in patients with coronary artery disease: a randomized trial. JAMA 2008;299:1903-13.

21 Leon MB, Mauri L, Popma JJ, et al. A randomized comparison of the endeavor zotarolimus-eluting stent versus the Taxus paclitaxeleluting stent in de novo native coronary lesions. J Am Coll Cardiol 2010;55:543-54.

22 Stone GW, Rizvi A, Newman W, et al. Everolimus-Eluting versus paclitaxel-eluting stents in coronary artery disease. $N$ Engl J Med 2010;362:1663-74.

23 Stefanini GG, Byrne RA, Serruys PW, et al. Biodegradable polymer drug-eluting stents reduce the risk of stent thrombosis at 4 years in patients undergoing percutaneous coronary intervention: a pooled analysis of individual patient data from the ISAR-TEST 3, ISAR-TEST 4, and leaders randomized trials. Eur Heart $J$ 2012;33:1214-22.

24 Kang S-H, Park KW, Kang D-Y, et al. Biodegradable-polymer drugeluting stents vs. bare metal stents vs. durable-polymer drug-eluting stents: a systematic review and Bayesian approach network metaanalysis. Eur Heart J 2014;35:1147-58.

25 Palmaz JC, Bailey S, Marton D, et al. Influence of stent design and material composition on procedure outcome. J Vasc Surg 2002;36:1031-9.

26 Abhyankar AD, Prajapati J, Reddy S. Early vascular healing with biodegradable polymer coated sirolimus-eluting coronary stent implantation: assessed by optical coherence tomography results at 4-month follow- up. Minerva Cardioangiologica 2013;61:313-22.

27 Shetty R, Prajapati J, Pai U. Preliminary evaluation of clinical and angiographic outcomes with biodegradable polymer coated sirolimuseluting stent in de novo coronary artery disease: results of the MANIPALFLEX study. Hindawi Publishing Corporation Scientifica 2016.

28 Pocock SJ, Lansky AJ, Mehran R, et al. Angiographic surrogate end points in drug-eluting stent trials: a systematic evaluation based on individual patient data from 11 randomized, controlled trials. J Am Coll Cardiol 2008;51:23-32.

29 Serruys PW, Ong AT, Piek JJ, et al. A randomized comparison of a durable polymer everolimus-eluting stent with a bare metal coronary stent: the spirit first trial. Eurolntervention 2005;1:58-65.

30 Costa RA, Lansky AJ, Abizaid A, et al. Angiographic results of the first human experience with the Biolimus A9 drug-eluting stent for de novo coronary lesions. Am J Cardiol 2006;98:443-6.

31 Meredith IT, Verheye S, Weissman NJ, et al. Six-Month IVUS and two-year clinical outcomes in the evolve FHU trial: a randomised evaluation of a novel bioabsorbable polymer-coated, everolimuseluting stent. Eurolntervention 2013;9:308-15.

32 Lemos PA, Chandwani P, Saxena S, et al. Clinical outcomes in 995 unselected real-world patients treated with an ultrathin biodegradable polymer-coated sirolimus-eluting stent: 12-month results from the flex registry. BMJ Open 2016;6:e010028. 
33 Finn AV, Joner M, Nakazawa G, et al. Pathological correlates of late drug-eluting stent thrombosis: strut coverage as a marker of endothelialization. Circulation 2007;115:2435-41.

34 Guagliumi G, Capodanno D, Ikejima H, et al. Impact of different stent alloys on human vascular response to everolimus-eluting stent: an optical coherence tomography study: the OCTEVEREST. Catheter Cardiovasc Interv 2013;81:510-8.

35 Gutiérrez-Chico JL, van Geuns RJ, Regar E, et al. Tissue coverage of a hydrophilic polymer-coated zotarolimus-eluting stent vs. a fluoropolymer-coated everolimus-eluting stent at 13-month followup: an optical coherence tomography substudy from the RESOLUTE all Comers trial. Eur Heart J 2011;32:2454-63.

36 Gutiérrez-Chico JL, Gijsen F, Regar E, et al. Differences in neointimal thickness between the Adluminal and the abluminal sides of Malapposed and side-branch Struts in a Polylactide Bioresorbable scaffold. JACC Cardiovasc Interv 2012;5:428-35.

37 Serruys PW, Silber S, Garg S, et al. Comparison of zotarolimuseluting and everolimus-eluting coronary stents. $N$ Engl J Med 2010;363:136-46.
38 Fajadet J, Neumann F-J, Hildick-Smith D, et al. Twelve-month results of a prospective, multicentre trial to assess the everolimus-eluting coronary stent system (PROMUS element): the platinum plus allcomers randomised trial. Eurolntervention 2017;12:1595-604.

39 Kereiakes DJ, Meredith IT, Windecker S, et al. Efficacy and safety of a novel bioabsorbable polymer-coated, everolimus-eluting coronary stent. Circulation 2015;8:e002372.

40 Pilgrim T, Heg D, Roffi M, et al. Ultrathin strut biodegradable polymer sirolimus-eluting stent versus durable polymer everolimuseluting stent for percutaneous coronary revascularisation (bioscience): a randomised, single-blind, non-inferiority trial. Lancet 2014;384:2111-22.

41 Zaman A, de Winter RJ, Kogame N, et al. Safety and efficacy of a sirolimus-eluting coronary stent with ultra-thin strut for treatment of atherosclerotic lesions (talent): a prospective multicentre randomised controlled trial. Lancet 2019;393:987-97. 